\title{
Effect of Oxygen Potential on Mineral Formation in Lime-fluxed Iron Ore
}

\section{Sinter}

\author{
Li-Heng HSIEH ${ }^{1)}$ and J.A. WHITEMAN ${ }^{2}$;
}

1) R \& D Department, China Steel Corporation, Kaohsiung, 81233, Taiwan, R.O.C

Sheffield, S1 3JD Yorkshire, U.K.

2) School of Materials, The University of Sheffietd,

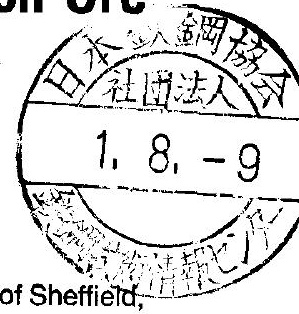

(Received on November 7, 1988; accepted in the final form on March 10, 1989)

\begin{abstract}
In industrial iron ore sintering, the raw material is heated in a reducing atmosphere and cooled in an oxidizing atmosphere. In order to study the characteristics of mineral formation under different regimes of heating and cooling in industrial sintering, small tablet specimens made from powdered materials were sintered in a tube furnace under controlled gas atmospheres. The results obtained are summarized as follows.

In the heating stage acicular calcium ferrite can be produced from the reaction of hematite and the flux below $1180^{\circ} \mathrm{C}$. With an increase of temperature, the calcium ferrite crystal size increases and at higher temperature the calcium ferrite transforms to magnetite and silicate melt. During the cooling stage, the magnetite tends to react with the silicate melt and oxygen to generate calcium ferrite at a medium oxygen partial pressure (around $1 \times 10^{-2} \mathrm{~atm}$ ). Reoxidized hematite is formed from magnetite at a higher oxygen potential (e.g., $5 \times 10^{-2}$ atm). The magnetite (produced in the heating stage) is preserved at a low oxygen potential. Acicular calcium ferrite may also be generated from magnetite ore at high oxygen potential (e.g., $P_{\mathrm{O}_{2}}>5 \times 10^{-3} \mathrm{~atm}$ ) during the heating stage of sintering.

Calcium ferrite produced from the reaction of hematite and the flux in heating stage is a form of calcium diferrite $\left(\mathrm{CaO} \cdot 2 \mathrm{Fe}_{2} \mathrm{O}_{3}\right)$ with some substitution of $\mathrm{Si}$ and $\mathrm{Al}$. The composition of calcium ferrite generated from magnetite depends on the amounts of $\mathrm{SiO}_{2}$ and $\mathrm{CaO}$ from silicate melt reacting with magnetite. The basicity (mole ratio of $\mathrm{CaO} / \mathrm{SiO}_{2}$ ) of silicate melt consumed in the reaction is around 2.
\end{abstract}

KEY WORDS: agglomeration; sintering; iron ore; simulation; atmosphere; mineral phases.

\section{Introduction}

In industrial iron ore sintering, the raw materials are heated in a reducing atmosphere and then cooled under an oxidizing atmosphere. The sinter mainly contains hematite, magnetite, calcium ferrite and glassy silicate. Although several mineral formation processes ${ }^{1-3}$ ) during sintering have been proposed, they were based on the experiments which the specimens were heated in air. Y. Hida et al.4) studied the effects of gas atmosphere on the minerals of sinter during the heating stage. Recently the authors ${ }^{5}$ reportcd that in the heating stage of sintering with an increase of heating temperature, the calcium ferrite transforms to hematite and silicate melt in a high oxygen potential atmosphere but transforms to magnetite, silicate melt and oxygen in the low oxygen potential atmosphere, which agrees with the proposals of Sasaki and Hida. ${ }^{3}$ Under the oxidizing cooling stage, magnetite may react with the silicate melt and oxygen to produce a large amount of calcium ferrite and also may oxidize to reoxidized hematite. However, the hematite phase (formed in the heating stage at a high oxygen potential) does not tend to react with the silicate melt to generate calcium ferrite in this stage.

In this investigation, the characteristics of the formation of minerals in heating and cooling stages were further studied under different gas atmospheres. Some relationships between mineral formation and gas atmosphere have been established.

\section{Experimental Procedure}

\subsection{Sample Preparation}

The raw materials for this study were MBR iron ore (a high grade hematite ore from Brazil), limestone, silica sand, and kaolin. Each was screened to obtain a particle size smaller than $0.25 \mathrm{~mm}$ before use. These materials were mixed as a standard hematite mixture. An artificial magnetite made from the reduction of MBR iron ore was also employed. The reduction was performed at $600^{\circ} \mathrm{C}$ for $24 \mathrm{~h}$ in the gas mixture of $\mathrm{CO} / \mathrm{CO}_{2}=1 / 10\left(P_{\mathrm{O}_{2}}=1.5 \times 10^{-23} \mathrm{~atm}\right)$. The product was checked by $\mathrm{X}$-ray diffraction and showed only magnetite. This magnetite, lime (calcined from limestone), silica sand, and dehydrated kaolin were mixed to give a magnetite mixture. Both mixtures which gave an overall chemical composition of sinter corresponding to $\mathrm{CaO}=13.5 \mathrm{wt} \%, \mathrm{SiO}_{2}=$ $6.5 \mathrm{wt} \%$, and $\mathrm{Al}_{2} \mathrm{O}_{3}=3.0 \mathrm{wt} \%$ were used to make the tablet specimens for sintering experiments. Table 1 shows the chemical compositions of raw materials and the blending ratios of raw materials in the mixtures.

Cylindrical tablets $6 \mathrm{~mm}$ diameter and approximately $6 \mathrm{~mm}$ in height were produced by pressing 
$0.4 \mathrm{~g}$ of the mixtures into a cylindrical mould for 1 min (the hematite mixture was bonded with $8 \mathrm{wt} \%$ water). The pressure of $0.45 \mathrm{~kg} / \mathrm{mm}^{2}$ was produced by a vertically loading piston. Before the tablet of hematite mixture was used for sintering, it was dried at $110^{\circ} \mathrm{C}$ for $3 \mathrm{~h}$.

\subsection{Sinlering}

The sintering apparatus is shown in Fig. 1, and consists essentially of a tube furnace. A gas mixture of controlled composition may be passed through the reaction tube $(25.4 \mathrm{~mm}$ diameter). The furnace was kept at a fixed controlling temperature. The specimen resting in the middle of a small fireclay combustion boat $72 \mathrm{~mm}$ long by $16 \mathrm{~mm}$ wide by $10 \mathrm{~mm}$ deep was pushed into the hot zone of the furnace. After the boat had been in the hot zone for the desired time, it was withdrawn for cooling by one of two methods. Either rapid cooling was used in which the boat was directly removed to the cool end of the reaction tube, or slow cooling was employed in which the boat was moved first to a location in the reaction tube at $140^{\circ} \mathrm{C}$ for $2 \mathrm{~min}$ before removal to the cool end of the tube.

In the reaction tube a $\mathrm{Pt}-\mathrm{Pt} \cdot 13 \% \mathrm{Rh}$ thermocouple at $10 \mathrm{~mm}$ away from the front of the combustion boat was used for controlling the sintering temperature. The relationships between temperature profiles measured by that and the thermocouples at various posi- tions of the specimen were obtained in advance. The actual sintering temperature was taken by averaging temperatures measured on the top surface of the specimen and $1 \mathrm{~mm}$ below the top surface in the specimen during sintering. Typical heating curves for sintering experiments are shown in Fig. 2. The maximum gas temperatures measured above the specimen (around 60 to $90^{\circ} \mathrm{C}$ higher than the maximum sintering temperatures) were used in the following chemical reaction and the standard free energy equation

$$
\begin{aligned}
& \mathrm{CO}+\frac{1}{2} \mathrm{O}_{2}=\mathrm{CO}_{2} \\
& \Delta G=-67500+20.757
\end{aligned}
$$

where, $\Delta G:$ standard free energy $(\mathrm{cal} / \mathrm{mol})$

$T$ : maximum gas temperature $(\mathrm{K})$

to calculate the oxygen potential of gas mixture containing $\mathrm{CO}$ gas in sintering.

During the experiments, the atmosphere was controlled by passing various gas mixtures into the reaction tube. The gases used were $\mathrm{CO}, \mathrm{CO}_{2}, \mathrm{~N}_{2}$, and air. Before the mixed gas flowed into the tube, it passed through a drying unit $(500 \mathrm{~mm}$ long by 30 mm diameter) filled with desiccant $\mathrm{CaSO}_{4}$. The gas flow rate was typically $300 \mathrm{ml} / \mathrm{min}$ and the rate of flow of each gas was measured by a flow meter. The working range of flow meter for each gas is $\mathrm{N}_{2}: 100$ to $1200 \mathrm{ml} / \mathrm{min}, \mathrm{CO}_{2}: 20$ to $250 \mathrm{ml} / \mathrm{min}, \mathrm{CO}: 3$ to 90 $\mathrm{m} / / \mathrm{min}$, Air: 3 to $90 \mathrm{ml} / \mathrm{min}$, and 40 to $700 \mathrm{ml} / \mathrm{min}$,

\begin{tabular}{|c|c|c|c|c|c|c|c|c|}
\hline \multirow{2}{*}{ Raw materials } & \multicolumn{6}{|c|}{ Chemical composition $(\%)$} & \multirow{2}{*}{$\begin{array}{l}\text { Ratios of } \\
\text { hematite } \\
\text { mixture } \\
(\%)\end{array}$} & \multirow{2}{*}{$\begin{array}{c}\text { Ratios of } \\
\text { magnetite } \\
\text { mixture* } \\
(\%)\end{array}$} \\
\hline & $\mathrm{TFe}$ & $\mathrm{SiO}_{2}$ & $\mathrm{Al}_{2} \mathrm{O}_{3}$ & $\mathrm{CaO}$ & $\mathrm{MgO}$ & Ig. loss & & \\
\hline MBR iron ore & 67.7 & 0.72 & 0.80 & 0.04 & 0.03 & 0.9 & 69.8 & 77.1 \\
\hline Limestone & 0.3 & 3.61 & 1.07 & 52.0 & 0.3 & 41.1 & 23.2 & 15.6 \\
\hline Silica sand & - & 99.9 & - & - & - & - & 2.3 & 2.6 \\
\hline Kaolin & 0.4 & 46.3 & 38.6 & 0.2 & 0.1 & 13.0 & 4.7 & 4.7 \\
\hline
\end{tabular}

Table 1. Chemical compositions of raw materials.

* Mixed by magnetite (reduced from MBR iron ore), lime (calcined from limestone), silica sand, and dehydrated kaolin.



Fig. 1. Sintering apparatus.

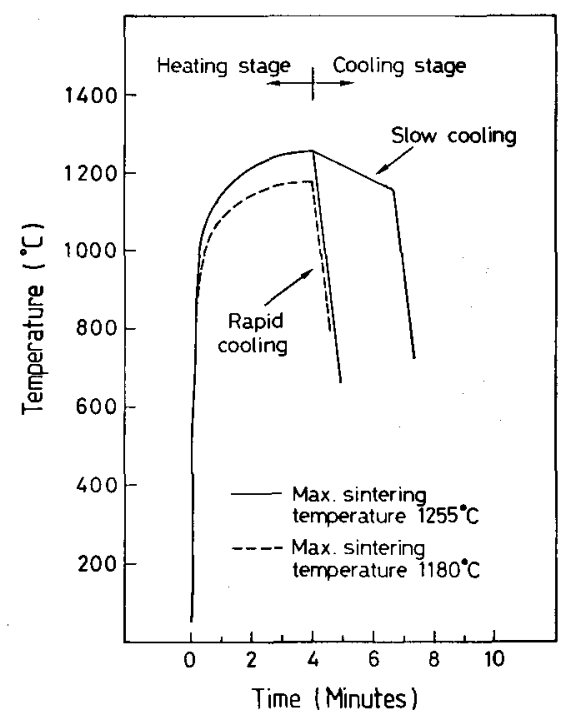

Fig. 2. Typical temperature/time profiles of sintering experiments. 
respectively. In order to obtain a particular controlled atmosphere, before the specimen was pushed into the tube, the tube was evacuated and then the gaseous mixture was passed through the tube for at least $8 \mathrm{~min}$ if the gas mixture was the same as that used in preceding test, otherwise for at least $30 \mathrm{~min}$. The cooling gas $\left(\mathrm{N}_{2}\right.$ or air) was directly led into the tube $20 \mathrm{~s}$ before the end of the heating stage to compensate for the time taken for the gas to reach the specimen. The exhaust gas outlet was connected to a silicone oil bubbler.

Normally industrial iron ore sinter does not contain wüstite, and therefore, the gas mixtures chosen for the experiments should prevent the formation of wüstite. From the calculation of thermodynamics, the gas mixture containing $\mathrm{CO} /\left(\mathrm{CO}+\mathrm{CO}_{2}\right)=0.08 \mathrm{can}$ be set as a top limit to the reduction atmosphere in sintering experiments. ${ }^{5}$ Other levels were chosen to give reasonable differences in oxygen potential below this limit. According to the authors' previous study, ${ }^{5}$ ) the gas mixture $\mathrm{CO}=1 \%, \mathrm{CO}_{2}=24 \%$, and $\mathrm{N}_{2}=75 \%$ is considered as a standard used in the experiments to simulate the industrial sintering in this study.

\subsection{Microstructure Analysis}

After sintering, the specimens were mounted in epoxy resin and then vacuum impregnated. The specimens were polished to expose a plane section corresponding to $1 \mathrm{~mm}$ below and parallel to the original top surface. These sections were polished by using silicon carbide paper to 1000 grit employing ethanol as a lubricant, and finally to $1 / 4$ micron finish by using diamond paste. During the wholc process, the specimens were not exposed to water.

After polishing, the specimens were studied under an optical microscope, Generally the typical microstructure of interior specimen was taken for the representative. In some experiments the microstructure on the surface was examined so that the oxygen potential in the reaction could be studied, since the oxygen potential on the surface of a specimen is close to that of the controlled gas mixture surrounding the specimen.

\subsection{Chemical Analysis of Phases in Sinter}

Analysis of phases in sinter were performed using a CAMSCAN 2 scanning electron microscope with an added LINK energy dispersive analysis system. The polished specimens with a reference cobalt on the surface were coated with carbon to ensure the surface to be examined was conducting. The quantitative analysis with ZAF corrections was obtained by using cobalt as a reference and pure hematite, calcite, recrystallized alumina, and quartz as standards. Throughout the work a filament voltage of $15 \mathrm{kV}$ was used. A spot size giving about 2500 counts per second was used. The analysis is accurate to within $\pm 5 \%$ of content.

\section{Results}

\subsection{Phase Transformations in Heating Stage}

The specimens made from the hematite mixture were heated for various times to different temperatures in a standard simulation gas mixture $(\mathrm{CO}=1 \%$, $\mathrm{CO}_{2}=24 \%$, and $\mathrm{N}_{2}=75 \%$ ) and then cooled rapidly in nitrogen to simulate the heating stage of industrial sintering.

From Figs. 3(A) and 3(B), it can be seen that the acicular calcium ferrite starts to form below $1185^{\circ} \mathrm{C}$. With an increase of heating temperature to $1220^{\circ} \mathrm{C}$ (at $2 \mathrm{~min}$ ), much more acicular calcium ferrite is generated. The sinter mainly contains acicular calcium ferrite and unreacted hematite. When the temperature was risen to $1245^{\circ} \mathrm{C}$ (at $3 \mathrm{~min}$ ), Fig. $3(\mathrm{C}$ ), the unreacted hematite disappears and the calcium ferrite

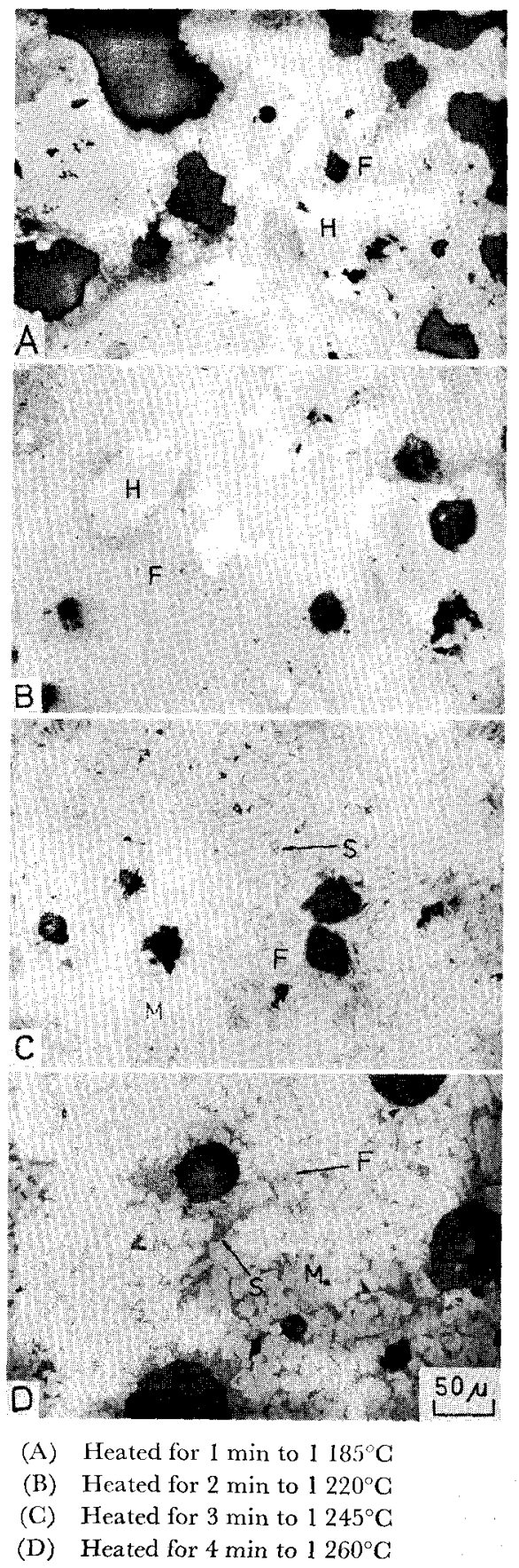

Fig. 3. Microstructures of the hematite mixture specimens heated for various times to different temperatures in the gas mixture $\mathrm{CO}=1 \%, \mathrm{CO}_{2}=24 \%$, and $\mathrm{N}_{2}=75 \%$ and then cooled rapidly in nitrogen. 
increases in crystal size. Some granular magnetite grains grow in the calcium ferrite structure. In comparison with the calcium ferrite structure in Fig. 3(B), it is clear that, these magnetite grains are formed from the dissociation of calcium ferrite. Some aggregated magnetite grains (with the thin calcium ferrite in grain boundary) can also be seen. This aggregate is probably reduced from the unreacted hematite. With the specimen heated for $4 \mathrm{~min}$ to $1260^{\circ} \mathrm{C}$, as shown in Fig. 3(D), the amount of calcium ferrite decreases greatly and is irregular shape; much more magnetite and glassy silicate are produced from it.

From the above, during the heating stage of industrial sintering, the acicular calcium ferrite is generated from the reaction of hematite and the flux (containing $\mathrm{CaO}, \mathrm{SiO}_{2}$, and $\mathrm{Al}_{2} \mathrm{O}_{3}$ ) initially. With an increase in heating temperature, the acicular calcium ferrite increases in amount and crystal size, and then dissociates to magnetite and a silicate melt.

\subsection{Effect of Heating Gas Atmosphere on the Formation of Acicular Calcium Ferrite}

The specimens containing hematite or magnetite were heated to a low temperature $\left(180^{\circ} \mathrm{C}\right)$ in various gas atmospheres and then cooled rapidly for this study. Figs. 4(A) to 4 (C) show that at a low sintering temperature $\left(180^{\circ} \mathrm{C}\right)$ the acicular calcium ferrite may be generated by hematite ore in the gas mixtures of $\mathrm{CO}=1 \%, \mathrm{CO}_{2}=24 \%$, and $\mathrm{N}_{2}=75 \% \quad\left(P_{\mathrm{O}_{2}}=2 \times\right.$ $10^{-8} \mathrm{~atm}$ calculated from gas composition and maximum gas temperature) and the higher oxygen partial pressure $\left(5 \times 10^{-3} \mathrm{~atm}\right)$ but no acicular calcium ferrite is formed in the gas mixture of $\mathrm{CO}=8 \%$ and $\mathrm{CO}_{2}=$ $92 \%\left(P_{\mathrm{O}_{2}}=5 \times 10^{-9} \mathrm{~atm}\right)$. However, Figs. 5(A) and $5(\mathrm{~B})$ show that with a magnetite ore, the acicular calcium ferrite is not formed in pure $\mathrm{CO}_{2}$ gas $\left(P_{\mathrm{O}_{2}}=2 \times\right.$ $10^{-4} \mathrm{~atm}$ ), but it is formed at the higher oxygen partial pressure $5 \times 10^{-3}$ atm (on the surface of specimen). The amount of acicular calcium ferrite increases with the oxygen potential (comparison of Figs. 5(B) and $5(\mathrm{C})$ ). From the above, it is clear that a higher oxygen potential favours to the formation of acicular calcium ferrite in the heating stage; the acicular calcium ferrite is produced from a hematite ore mixture at a lower oxygen potential. From Figs. 5(B) and $5(\mathrm{C})$, it can also be seen that when the oxygen potential increases to $5 \times 10^{-2}$ atm, the magnetite oxidizes to hematite and the porosity increases.

The pure magnetite ore (without flux) specimens heated under the same conditions (to $1180^{\circ} \mathrm{C}$ ) show that at the oxygen potential $5 \times 10^{-3}$ atm, a considerable amount of magnetite oxidizes to hematite on the surface of specimen, as shown in Fig. 6. The amount of this hematite also increases with the oxygen potential. For this reason, during the heating stage, the hematite may be an intermediate phase for the formation of acicular calcium ferrite in the magnetite mixture. It is supposed that under a higher oxygen potential atmosphere, magnetite initially oxidizes to hematite. Subsequently the acicular calcium ferrite is generated from the reaction of the hematite and flux.



(A) Hcating: $\quad \mathrm{O}_{2}=0.5 \%, \mathrm{~N}_{\mathrm{z}}=99.5 \%$ $\left(P_{\mathrm{O}_{2}}=5 \times 10^{-3} \mathrm{~atm}\right)$

Cooling: The same as heating

(B) Heating: $\mathrm{CO}=1 \%, \mathrm{CO}_{2}=24 \%, \mathrm{~N}_{2}=75 \%$ $\left(P_{0 a}=2 \times 10^{-8} \mathrm{~atm}^{*}\right)$ Cooling: $\mathrm{N}_{2}=100 \%$

(C) Heating: $\mathrm{CO}=8 \%, \mathrm{CO}_{2}=92 \%$ $\left(P_{\mathrm{O}_{2}}=5 \times 10^{-9} \mathrm{~atm} *\right)$ Cooling: $\mathrm{N}_{2}=100 \%$

* Calculation value, see experimental procedure

Fig. 4. Microstructures of the hematite mixture specimens heated for $4 \mathrm{~min}$ to $180^{\circ} \mathrm{C}$ in various gas mixtures and then cooled rapidly. (The maximum gas temperature is $1244^{\circ} \mathrm{C}$.)

\subsection{Effect of Cooling Gas Atmosphere on Minerals}

The surface microstructures of the hematite mixture specimens heated for $4 \mathrm{~min}$ to $1255^{\circ} \mathrm{C}$ in various gas mixtures and then cooled in that same gas mixture were examined. With a slow cooling rate, the surface of the specimen cooled in a low oxygen potential atmosphere $\left(9 \times 10^{-8} \mathrm{~atm}\right)$ contains magnetite and glassy silicate, see Figs. $7(\mathrm{~A})$ to $7(\mathrm{G})$. With an increase of oxygen potential to $5 \times 10^{-3} \mathrm{~atm}$, a little calcium ferrite is generated on the surface; and more calcium ferrite is formed at the oxygen potential $1 \times 10^{-2} \mathrm{~atm}$. When the specimen is cooled in a higher oxygen potential $\left(5 \times 10^{-2} \mathrm{~atm}\right)$, a large amount of reoxidized hematite is formed on the surface, see Fig. 7(D).

Regarding the rapidly cooled specimens, the surface of the specimen heated in the oxygen potential 


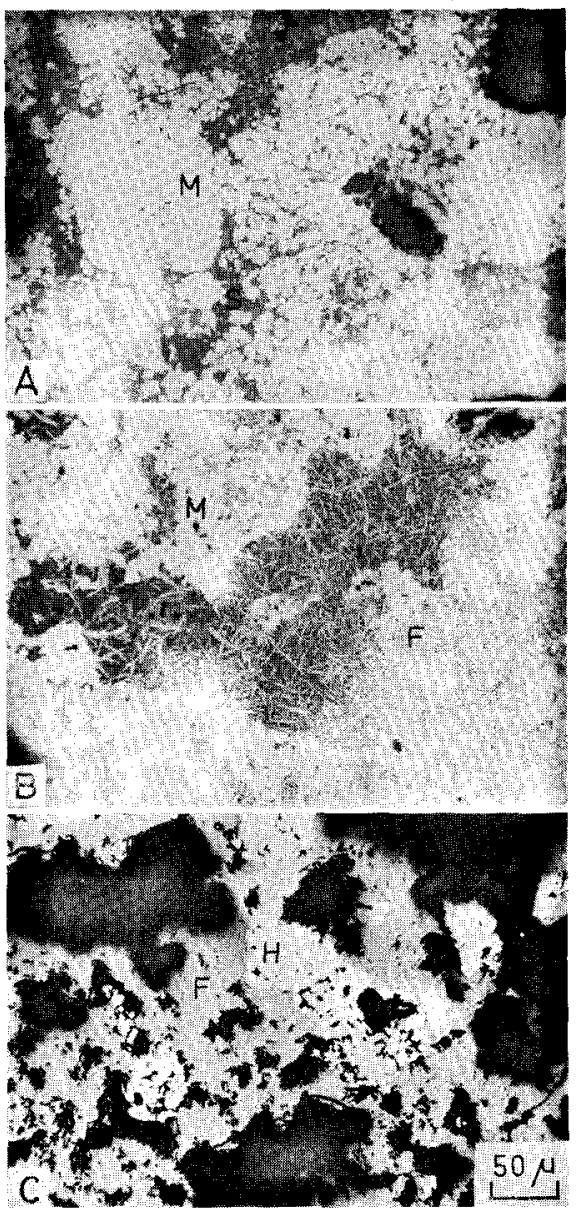

(A) $\mathrm{CO}_{2}=100 \%\left(P_{\mathrm{O}_{2}}=2 \times 10^{-4} \mathrm{~atm}^{*}\right)$

(B) $\mathrm{O}_{2}=0.5 \%, \mathrm{~N}_{2}=99.5 \%$ $\left(P_{\mathrm{O}_{2}}=5 \times 10^{-3} \mathrm{~atm}\right)$

(C) $\mathrm{O}_{2}=5 \%, \mathrm{~N}_{2}=95 \%$ $\left(P_{\mathrm{O}_{2}}=5 \times 10^{-2} \mathrm{~atm}\right)$

* Calculation value

Fig. 5. Surface microstructures of the magnetite mixture specimens heated for $4 \mathrm{~min}$ to $1180^{\circ} \mathrm{C}$ in various gas mixtures and then cooled rapidly in the same gas mixture as heating. (The maximum gas temperature is $1244^{\circ} \mathrm{C}$.)

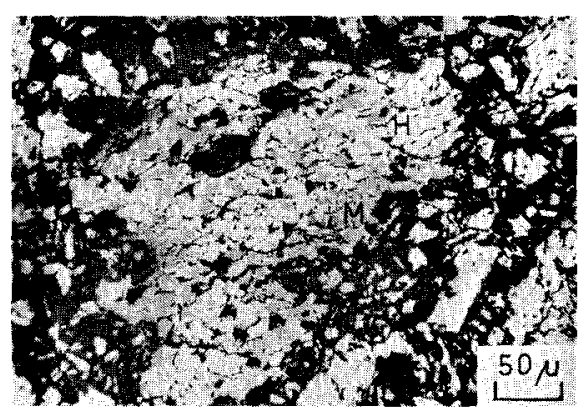

Fig. 6. Microstructure of the pure magnetite powder heated for $4 \mathrm{~min}$ to $1180^{\circ} \mathrm{C}$ in the gas mixture $\mathrm{O}_{2}=0.5 \%, \mathrm{~N}_{2}=99.5 \%\left(P_{\mathrm{O}_{2}}=5 \times 10^{-3} \mathrm{~atm}\right)$ and then cooled rapidly in the same gas mixture as heating.

$1 \times 10^{-2} \mathrm{~atm}$ atmosphere contains magnetite and silicate melt (but not calcium ferrite) in the heating stage, see Fig. 8(A). Therefore, the calcium ferrite
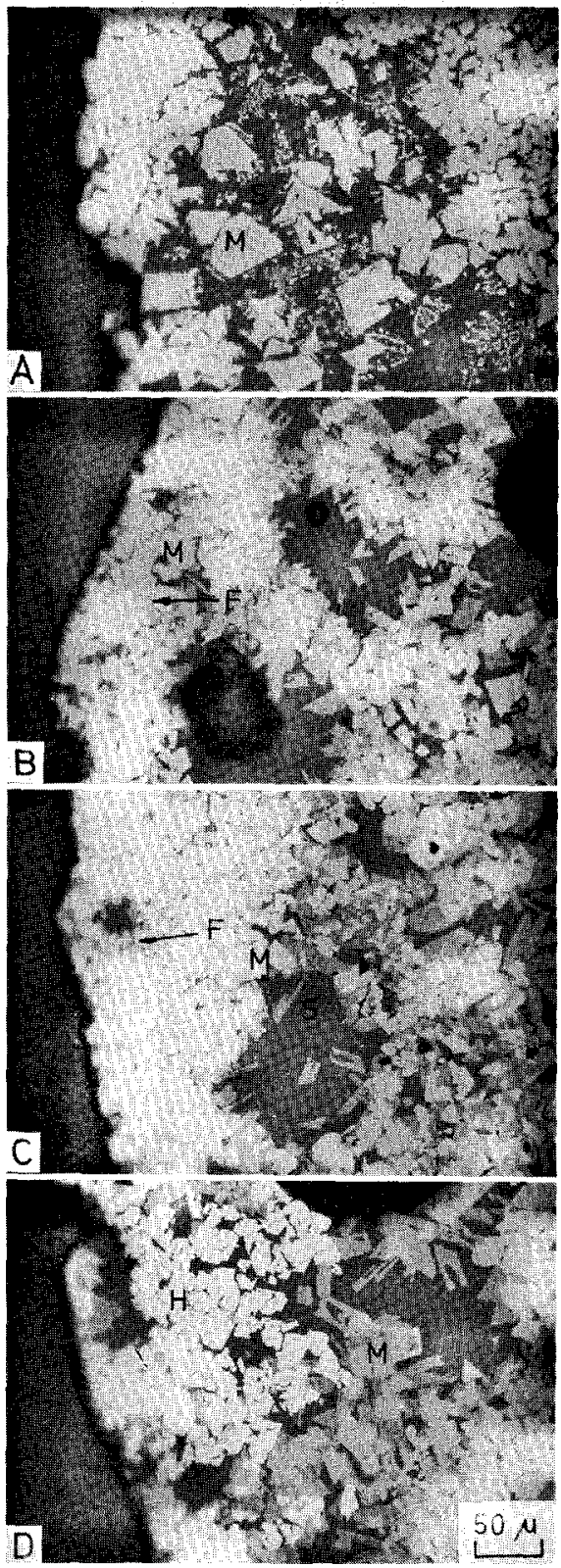
(A) $\mathrm{CO}=8 \%, \mathrm{CO}_{2}=92 \%$
$\left(P_{\mathrm{O}_{2}}=9 \times 10^{-8} \mathrm{~atm}^{*}\right)$
(B) $\mathrm{O}_{2}=0.5 \%, \mathrm{~N}_{2}=99.5 \%$
$\left(P_{\mathrm{O}_{2}}=5 \times 10^{-3} \mathrm{~atm}\right)$
(C) $\mathrm{O}_{2}=1 \%, \mathrm{~N}_{2}=99 \%$
$\left(P_{\mathrm{O}_{2}}=1 \times 10^{-2} \mathrm{~atm}\right)$
(D) $\mathrm{O}_{2}=5 \%, \mathrm{~N}_{2}=95 \%$
$\left(P_{\mathrm{O}_{2}}=5 \times 10^{-2} \mathrm{~atm}\right)$

* Calculation value

Fig. 7. Surface microstructure of the hematite mixture specimens heated for $4 \mathrm{~min}$ to $1255^{\circ} \mathrm{C}$ in various gas mixtures and then cooled slowly in the same gas mixture as hcating. (The maximum gas temperature is $1345^{\circ} \mathrm{C}$.)

on the surface of the specimens (in Figs. 7(B) and $7(\mathrm{C})$ ) is generated in the slow cooling stage. A rapid cooling process may preserve the minerals formed in the heating stage and retard the formation of calcium ferrite. Again, since Fig. 8(B) shows only a little reoxidized hematite formed during the rapid cooling, in comparison with Fig. $7(\mathrm{D})$, a slow cooling rate 


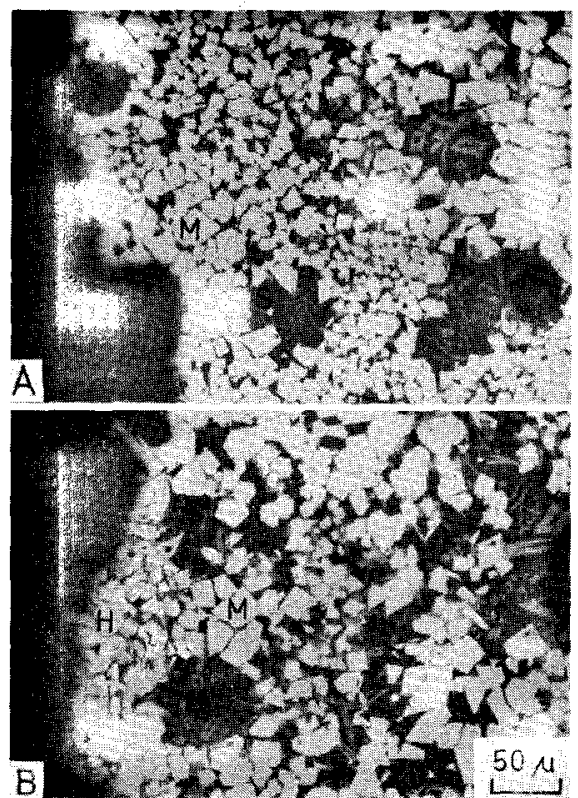

(A) $\mathrm{O}_{2}=1 \%, \mathrm{~N}_{2}=99 \%$

$\left(P_{\mathrm{O}_{2}}=1 \times 10^{-2} \mathrm{~atm}\right)$

(B) $\mathrm{O}_{2}=5 \%, \mathrm{~N}_{2}=95 \%$

$\left(P_{\mathrm{O}_{u}}=5 \times 10^{-2} \mathrm{~atm}\right)$

Fig. 8. Surface microstructure of the hematite mixture specimens heated for $4 \mathrm{~min}$ to $1255^{\circ} \mathrm{C}$ in various gas mixtures and then cooled rapidly in the same gas mixture as heating.

favours the oxidation of magnetite to hematite at a high oxygen potential.

From the above, during the cooling stage, calcium ferrite tends to be generated (from magnetite and silicate melt $\left.{ }^{5}\right)$ at a medium partial pressure of oxygen (around $1 \times 10^{-2} \mathrm{~atm}$ ). The formation of reoxidized hematite occurs at a high oxygen potential and the magnetite (formed in the heating stage) is preserved in the low oxygen potential atmosphere.

\subsection{Morphology of Calcium Ferrite}

From Figs. 3(A), 3(B), 4(A), and 4(B), it can be seen that a low sintering temperature favours to the formation of acicular calcium ferrite during heating stage. With an increase of heating temperature and time, the calcium ferrite transforms from acicular type through columnar to irregular (as shown in Figs. 3(B) to $3(\mathrm{D}))$.

The acicular calcium ferrite may also be formed during cooling. With the specimens heated to $1210^{\circ} \mathrm{C}$ in 3 min, from comparison of Figs. 9(A) and $9(\mathrm{~B})$, it is clear that much of the acicular calcium ferrite in Fig. 9(B) is formed by reaction of magnetite and the silicate melt in the oxidizing cooling stage. Howcver, when the specimen was heated to the higher heating temperature $\left(1255^{\circ} \mathrm{C}\right)$ in a longer heating time $(4$ min), the calcium ferrite formed in the cooling stage becomes columnar (as shown in Fig. 10).

Fig. 11 shows an eutectic structure of calcium ferrite. This structure can be generated by heating the hematite mixture specimen (to $1255^{\circ} \mathrm{C}$ in $4 \mathrm{~min}$ ) in a high reducing potential atmosphere (the gas mix-

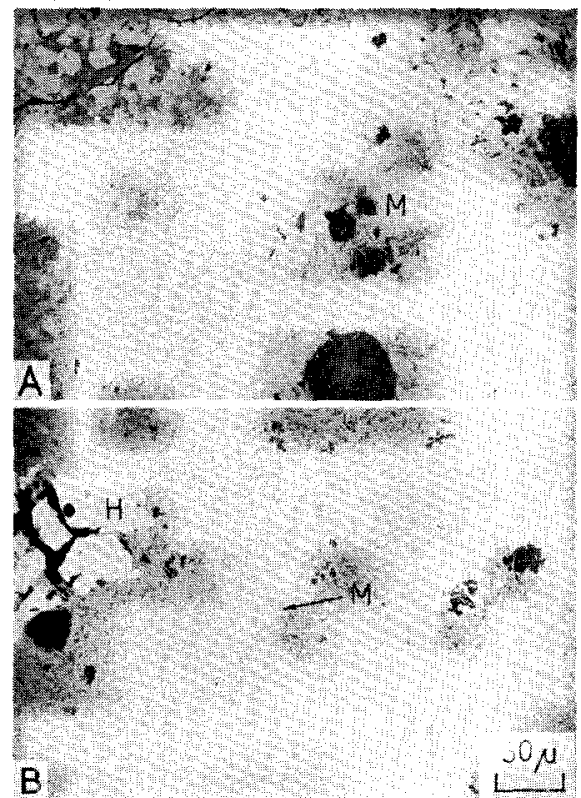

(A) Rapid cooling in nitrogen

(B) Slow cooling in air

Fig. 9. Microstructures of the hematite mixture specimens heated for $3 \mathrm{~min}$ to $1210^{\circ} \mathrm{C}$ in the standard simulation gas mixture $\left(\mathrm{CO}=1 \%, \mathrm{CO}_{2}=24 \%\right.$, and $\mathrm{N}_{2}=$ $75 \%$ ) and then cooled in different ways.



Fig. 10. Microstructure of the hematite mixture specimens heated for $4 \mathrm{~min}$ to $1255^{\circ} \mathrm{C}$ in the standard simulation gas mixture $\left(\mathrm{CO}=1 \%, \mathrm{CO}_{2}=24 \%\right.$, and $\mathrm{N}_{2}=75 \%$ ) and then cooled slowly in air.



Fig. 11. Microstructure of the hematite mixture specimen heated for $4 \mathrm{~min}$ to $1255^{\circ} \mathrm{C}$ in a high reducing gas mixture $\left(\mathrm{CO}=8 \%, \mathrm{CO}_{2}=92 \%\right)$ and then cooled slowly in nitrogen.

ture $\mathrm{CO}=8 \%, \mathrm{CO}_{2}=92 \%$ ) and then cooling slowly in nitrogen or the reducing atmosphere used in heating. 


\subsection{Chemical Composition of Calcium Ferrite}

The minerals in sinters were analysed by using the energy dispersive X-ray system on an SEM to get their chemical compositions. The specimens for this study are described in Table 2.

Comparison of calcium ferrite compositions (in Fig. 12) and the related microstructures (in Fig. 3), the following phenomena during heating are observed. In the initial heating stage (the specimen heated for $1 \mathrm{~min}$ to $1185^{\circ} \mathrm{C}$ ), the raw materials are partially reacted and acicular calcium ferrite forms (as shown in Fig. 3(A)). This acicular calcium ferrite contains $\mathrm{Al}_{2} \mathrm{O}_{3}$ around $5 \mathrm{~mol} \%$, a relatively low $\mathrm{SiO}_{2}$ content (around $9 \mathrm{~mol} \%$ ), and $\mathrm{CaO}$ content at about 29 $\mathrm{mol} \%$ (as shown in Fig. 12), hence it is considered to be a form of calcium diferrite $\left(\mathrm{CaO} \cdot 2 \mathrm{Fe}_{2} \mathrm{O}_{3}\right)$ with some substitution of $\mathrm{Si}$ and $\mathrm{Al}$. When the temperature is increased to $1220^{\circ} \mathrm{C}$, except for partially unreacted hematite, all the materials are assimilated into the reaction to form a large amount of acicular calcium ferrite (as shown in Fig. 3(B)). In comparison with the composition of previous acicular calcium ferrite, the ferrite produced in this stage contains a higher $\mathrm{SiO}_{2}$ content (around $14 \mathrm{~mol} \%$ ), a slightly lower $\mathrm{CaO}$ content (around $26 \mathrm{~mol} \%$ ), and the same level of $\mathrm{Al}_{2} \mathrm{O}_{3}$. It is also thought to be a form of calcium diferrite. With an increase of temperature to $1245^{\circ} \mathrm{C}$ (at $3 \mathrm{~min}$ ), the acicular calcium ferrite increases in crystal size and some of it transforms into magnetite and a silicate melt; the unreacted hematite is assimilated and converted into magnetite and calcium ferrite (as shown in Fig. 3(G)). From Fig. 12, it can be seen that the ranges of $\mathrm{CaO}$ and $\mathrm{SiO}_{2}$ contents in calcium ferrite extend. The calcium ferrite containing low levels of $\mathrm{CaO}$ and $\mathrm{SiO}_{2}$ (for example, $\mathrm{CaO}$ $19.4 \mathrm{~mol} \%$ and $\mathrm{SiO}_{2} 6.9 \mathrm{~mol} \%$ ) is not likely to be a form of calcium diferrite. When the temperature is increased to $1260^{\circ} \mathrm{C}$, as shown in Fig. 3(D), much of calcium ferrite transforms into magnetite and a silicate melt. The residual ferrite contains a relatively higher levels of $\mathrm{CaO}$ (around $29 \mathrm{~mol} \%$ ) and $\mathrm{SiO}_{2}$ (around $14 \mathrm{~mol} \%$ ), as shown in Fig. 12. The $\mathrm{Al}_{2} \mathrm{O}_{3}$ content does not change obviously.

From the above, during heating the substituted calcium diferrite is generated initially. Afterwards, its composition varies with the maximum temperature attained.

Fig. 13 shows that although most of calcium ferrite contains $\mathrm{CaO}$ at around 25 to $30 \mathrm{~mol} \%$, the $\mathrm{CaO}$ and $\mathrm{SiO}_{2}$ contents of calcium ferrite range from 17 to 31 $\mathrm{mol} \%$ and 6 to $16 \mathrm{~mol} \%$, respectively in this study (from specimens $\mathrm{A} 1$ to $\mathrm{A} 6$ ). 'This includes the calcium ferrite formed during heating and cooling stages. Except for a few substituted calcium diferrite generated in the initial heating stage (specimen $\mathrm{Al}$ ), the compositions of calcium ferrite lie around a line connecting $2 \mathrm{CaO} \cdot \mathrm{SiO}_{2}$ and a substituted magnetite (analysed in specimen A3) whose composition is modified in the form of hematite on the ternary phase diagram. The large variation of compositions on this line is probably caused by the calcium ferrite formed from magnetite reacting with various amounts of $\mathrm{CaO}$ and
Table 2. Specimens of hematite mixture for analysing the chemical composition of minerals.

\begin{tabular}{ccclll}
\hline \multirow{2}{*}{ Specimen } & \multicolumn{2}{c}{ Heating condition } & & \multicolumn{2}{c}{ Cooling condition } \\
\cline { 2 - 3 } & $\begin{array}{c}\text { Max. temp. } \\
\left({ }^{\circ} \mathrm{C}\right)\end{array}$ & $\begin{array}{c}\text { Time } \\
\text { (min) }\end{array}$ & & Speed & Gas \\
\hline A1 & 1185 & 1 & Rapid & $\mathrm{N}_{2}$ \\
A2 & 1220 & 2 & Rapid & $\mathrm{N}_{2}$ \\
A3 & 1245 & 3 & Rapid & $\mathrm{N}_{2}$ \\
A4 & 1260 & 4 & Rapid & $\mathrm{N}_{2}$ \\
A5 & 1245 & 3 & Slow & Air \\
A6 & 1260 & 4 & Slow & Air \\
\hline
\end{tabular}



Max heating temp. and heating time

Fig. 12. Variation of chemical compositions of calcium ferrite in the heating stage.

$\mathrm{SiO}_{2}$ (from silicate melt). The bacisity (mole ratio of $\mathrm{CaO} / \mathrm{SiO}_{2}$ ) of silicate melt consumed in the reaction is around 2.

\section{Discussion}

(1) According to the experimental results and the authors' previous report, ${ }^{5)}$ a schematic outline of the mineral formation process is shown in Fig. 14 and described as follows:

(a) During the heating stage, the acicular calcium ferrite can be generated from the reaction of hematite or magnetite with the flux below a temperature of $1180^{\circ} \mathrm{C}$. Hematite forms at a lower oxygen potential than does magnetite.

(b) When calcium ferrite forms, it is stable at the high oxygen potential atmosphere and low tempera- 


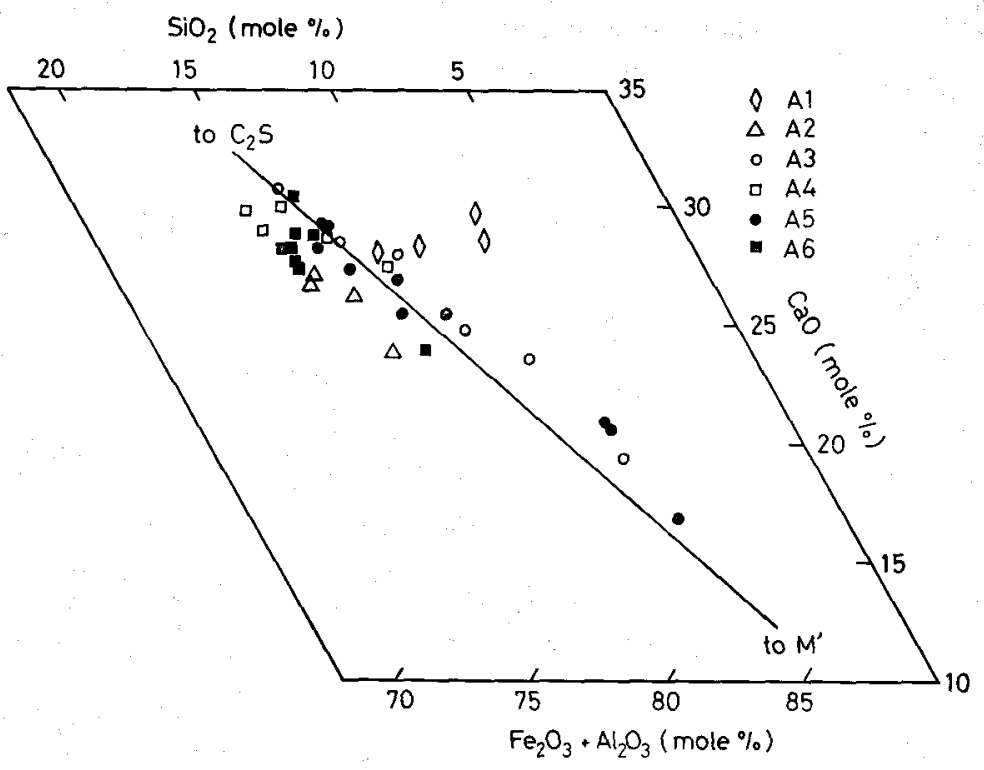

$\mathrm{C}_{2} \mathrm{~S}: 2 \mathrm{CaO} \cdot \mathrm{SiO}_{2}$

$M^{\prime}$ : A substituted magnetite (analysed in specimen A3) whose composition is modified in the form of hematite $\left(\mathrm{Fe}_{2} \mathrm{O}_{3}+\mathrm{Al}_{2} \mathrm{O}_{3}=92.1\right.$ $\mathrm{mol} \%, \mathrm{CaO}=6.2 \mathrm{~mol} \%$, and $\mathrm{SiO}_{2}=1.7$ $\mathrm{mol} \%$ )

Fig. 13.

Chemical compositions of calcium ferrite formed in heating and cooling stages.



ture. If the environment changes to a low oxygen potential and high temperature, calcium ferrite transforms to magnetite and a silicate melt. If calcium ferrite is in an cnvironment of the high oxygen potential atmosphere (air) and at temperature around $1255^{\circ} \mathrm{C}$, it will transform to hematite and a silicate melt. ${ }^{5)}$ 'This phenomenon was also proposed by Sasaki and Hida. ${ }^{3)}$

(c) During the cooling stage, in a medium oxygen potential (around $1 \times 10^{-2} \mathrm{~atm}$ ), magnetite tends to react with the silicate melt and oxygen to form calcium ferrite. If magnetite meets the high oxygen potential, it will oxidize to hematite (reoxidized hematite). If the environment is low in oxygen potential, magnetite is preserved. However, the hematite phase formed in the heating stage (at a high oxygen potential) does not tend to react with silicate melt to generate calcium ferrite during the cooling stage in air. ${ }^{5}$

(2) In order to produce a large amount of acicular calcium ferrite to improve the properties of sinter, two methods may be employed. One is to generate the acicular calcium ferrite and avoid it transforming to the columnar form or dissociated to magnetite and a silicate melt during the heating stage. The other is to provide a favourable cooling regime to produce calcium ferrite from the reaction of magnetite, silicate melt and oxygen. No matter which way is used, a low heating temperature is beneficial to the formation of acicular calcium ferrite. However, if the heating temperature is too low, the acicular calcium ferrite can not be produced in large amounts and the structure of the sinter will be too porous and weak (as shown in Fig. 3(A)). Therefore, to make an ideal mineral structure in sinter, an optimum combination of temperature profile and gas atmosphere should be applied.

In industrial sintering, the temperature profile of the bed varies from top to bottom. The maximum heating temperature is lower and retention time at high temperature is shorter at the bed top than at the bottom. In this case, minimizing the difference in temperature profile and controlling it to a suitable heat pattern is important to improve the mineral structure of sinter.

(3) In the microstructure of a self-fluxed indus- 
trial sinter, reoxidized hematite normally surrounds on the pores. The typical microstructure of the bond is composed of a large amount of columnar calcium ferrite with granular magnetite grains and a little glassy silicate, but a small amount of the bond may contain a lot of magnetite with glassy silicate and a little calcium ferrite. ${ }^{5}$ The formation of these microstructures may be explained by the characteristics of the mincral reaction as follows.

In the hcating stage of industrial sintering, a large amount of calcium ferrite dissociates to magnetite and a silicate melt. During the cooling stage, near the pores the magnetite is cooled in a high oxygen potential atmosphere and tends to oxidize to hematite. Therefore, the reoxidized hematite is present near the pores. Most of the other places in which oxygen diffuses are cooled at a medium oxygen potential. The magnetite there will react with a silicate melt and oxygen to produce a large amount of columnar calcium ferrite. Thus the typical microstructure of the bond is formed. If the region is near to coke and distant from the pores, it is cooled in a low oxygen potential. The magnetite formed in the heating stage will be preserved in it. This region will contain a large amount of magnetite.

From the characteristics of the reaction of magnetite, it can be deduced that theoretically, if the area of the medium oxygen potential atmosphere (around $\left.1 \times 10^{-2} \mathrm{~atm}\right)$ is extended in the cooling stage, the proportion of calcium ferrite may be increased on sintering.

(4) From the experimental results, during heating (at $1180^{\circ} \mathrm{C}$ ), the acicular calcium ferrite is formed from the magnetite mixture at an oxygen partial pressure higher than $5 \times 10^{-3}$ atm (Figs. 5(B) and $5(\mathrm{C})$ ), but it can be produced from hematite at a lower oxygen potential (e.g., the gas mixture $\mathrm{CO}=$ $1 \%, \mathrm{CO}_{2}=24 \%$, and $\mathrm{N}_{2}=75 \%, P_{\mathrm{O}_{2}}=2 \times 10^{-8} \mathrm{~atm}$ ). With a hematite mixture, in the initial heating stage the acicular calcium ferrite is generated from the reaction of hematite and the flux. Because the sintering reaction does not reach equilibrium in that lower oxygen potential atmosphere, the acicular calcium ferrite is preserved in the sinter.

(5) Matsuno $^{1)}$ and Matsuno and Harada ${ }^{2)}$ reported that during the heating process calcium ferrite was formed by reaction between hematite and lime. When calcium ferrite was melted at the higher temperature, gangue minerals containing $\mathrm{SiO}_{2}$ dissolved into the melt and the iron oxides were precipitated. During cooling, the formation of minerals depended on the basicity $\left(\mathrm{CaO} / \mathrm{SiO}_{2}\right)$ of melt. If the bascity was high, the calcium ferrite and dicalcium silicate were generated from the melt; otherwise a glassy silicate and hematite were formed.

However, different phenomena can be seen in this study. In the initial heating stage, hematite reacts with lime and a little $\mathrm{SiO}_{2}$ and $\mathrm{Al}_{2} \mathrm{O}_{3}$ to form the substituted calcium diferrite with a relatively low $\mathrm{SiO}_{2}$ content (around $9 \mathrm{~mol} \%$ ). With an increase of temperature, after more quartz is assimilated by the reaction, the calcium ferrite is able to accept more $\mathrm{SiO}_{2}$ (up to around $14 \mathrm{~mol} \%$ ). When the calcium ferrite is dissociated, magnetite and a silicate melt are produced (if it is in the low oxygen potential). During cooling, this magnetite may react with the silicate melt and oxygen to generate a large amount of calcium ferrite and also may oxidize to hematite. The basicity (mole ratio of $\mathrm{CaO} / \mathrm{SiO}_{2}$ ) of silicate melt consumed in this reaction is around 2 .

(6) Inouc and $1 \mathrm{keda}^{6)}$ proposed that the calcium ferrite is a solid solution consisting of $\mathrm{CaSiO}_{3} \mathrm{Ca}(\mathrm{Fe}$, $\mathrm{Al})_{6} \mathrm{O}_{10}$. The $\mathrm{SiO}_{2}$ component was found to dissolve into the ferrite continuously up to $12 \mathrm{~mol} \%$ at 1250 ${ }^{\circ} \mathrm{C}$. This implies that the $\mathrm{CaO}$ content in calcium ferrite is at least $25 \mathrm{~mol} \%$. However, the calcium ferrite formed in this study contains $\mathrm{CaO}$ between 17 to $31 \mathrm{~mol} \%$ and $\mathrm{SiO}_{2}$ up to $16 \mathrm{~mol} \%$. This does not follow the definition of a solid solution consisting of $\mathrm{CaSiO}_{3}-\mathrm{Ca}(\mathrm{Fc}, \mathrm{Al})_{6} \mathrm{O}_{10}$.

Ahsan $e t a l{ }^{7)}$ reported that the calcium ferrite has a wide range of composition associated with one type of crystal structure, a superlattice of magnetite. Its composition can be considered as a substitution of $\mathrm{Al}$, $\mathrm{Si}$, and $\mathrm{Ca}$ atoms into the magnetite lattice in place of iron atoms. Their investigation can support the proposal that magnetite reacts with various amounts of $\mathrm{CaO}$ and $\mathrm{SiO}_{2}$ (from melt) to form the calcium ferrite with a wide range of composition. Thus the composition of this ferrite is probably related to amounts of constituents $\left(\mathrm{CaO}, \mathrm{SiO}_{2}\right.$, and $\left.\mathrm{Al}_{2} \mathrm{O}_{3}\right)$ surrounding the magnetite and reaction temperature.

(7) Coheur ${ }^{81}$ proposed that the structure of calcium ferrite was derived from calcium diferrite $\mathrm{CaO}$. $2 \mathrm{Fe}_{2} \mathrm{O}_{3}$ and the general formula was $x \mathrm{Fe}_{2} \mathrm{O}_{3} \cdot y \mathrm{SiO}_{2}$. $z \mathrm{Al}_{2} \mathrm{O}_{3} \cdot 5 \mathrm{CaO}$ where $x+y+z=12$. This formula implies that the $\mathrm{CaO}$ content in calcium ferrite is around $29.4 \mathrm{~mol} \%$. The study of Dawson et al. ${ }^{9)}$ confirmed the above proposal. Sasaki et al. ${ }^{10)}$ also supposed that the calcium ferrite in iron ore sinter was calcium diferrite containing $\mathrm{Al}_{2} \mathrm{O}_{3}$. In this study, the calcium ferrite generated from hematite, lime, silica, and kaolin in the initial heating stage contains $\mathrm{CaO}$ about $29 \mathrm{~mol} \%$ and a little $\mathrm{Al}_{2} \mathrm{O}_{3}$ and $\mathrm{SiO}_{2}$. Therefore, it is also considered to be the substituted calcium diferrite. However, during sintering the composition of this ferrite may vary. It is probably controlled by the diffusion of $\mathrm{Si}, \mathrm{Ca}$, and $\mathrm{Al}$ which is related to temperature and the amounts of constituents ( $\mathrm{CaO}$, $\mathrm{SiO}_{2}$, and $\mathrm{Al}_{2} \mathrm{O}_{3}$ ) surrounding the ferrite. For example, when calcium ferrite exists with a silicate melt (rich in $\mathrm{CaO}$ and $\mathrm{SiO}_{2}$ ) at high temperature (as shown in Fig. 3(D)), it will contain the high levels of $\mathrm{CaO}$ and $\mathrm{SiO}_{2}$.

The calcium ferrite containing low levels of $\mathrm{SiO}_{2}$ and $\mathrm{CaO}$ was also found in small amounts during heating (as shown in Fig. 12). Because of the significantly different composition of this ferrite relative to the substituted calcium diferrite, the mechanism of their formations should be different. From Fig. 3(B) and $3(\mathrm{G})$, it can be seen that the assimilation of unreacted hematite will produce magnetite and calcium ferrite. The mechanism of the assimilation of hematite may be considered as follows: 
(a) The surface of unreacted hematite is reduced to magnetite.

(b) During the continuous reduction of the internal unreacted hematite, oxygen is released and diffuses outwards. When the $P_{\mathrm{O}_{2}}$ near the particle surface increases to a certain extent, the magnetite will reacts with the silicate melt and oxygen to form calcium ferrite at the surface.

(c) The above reactions continue and penetrate through the unreacted hematite.

It is probably that because of the lack of the melt consisting of $\mathrm{SiO}_{2}$ and $\mathrm{CaO}$ associated with unreacted hematite, the magnetite produced by reduction reacts with only limited amounts of $\mathrm{CaO}$ and $\mathrm{SiO}_{2}$. Thus the calcium ferrite formed from the unreacted hematite area may contain low $\mathrm{CaO}$ and $\mathrm{SiO}_{2}$ contents.

\section{Conclusion}

In this study, the characteristics of mineral formation during iron ore sintering were determined by the laboratory sintering experiments. The results obtained are as follows.

(1) In the heating stage of industrial sintering, the acicular calcium ferrite can be produced from the reaction of hematite and the flux below $1180^{\circ} \mathrm{C}$. With an increase of temperature, it increases in crystal size and then transforms to magnetite and a silicate melt. During the cooling stage, the magnetite tends to react with the silicate melt and oxygen to generate calcium ferrite at the medium oxygen partial pressure (around $1 \times 10^{-2} \mathrm{~atm}$ ). Reoxidized hematite is formed from the oxidation of magnetite in the higher oxygen potential (e.g., $5 \times 10^{-2}$ atm). The magnetite (produced in the heating stage) is preserved in the lower oxygen potential.

(2) The acicular calcium ferrite may also be generated from magnetite ore at a high oxygen potential (e.g., $P_{\mathrm{O}_{2}}>5 \times 10^{-3}$ atm) in the heating stage of sinter- ing.

(3) The calcium ferrite transforms from acicular type through columnar io irregular in the heating of industrial sintering. The acicular calcium ferrite may also be produced in the cooling stage. The crystal size of calcium ferrite formed in cooling increases with the heating temperature and time.

(4) Calcium ferrite produced from the reaction of hematite and the flux in heating stage is a form of calcium diferrite $\left(\mathrm{CaO} \cdot 2 \mathrm{Fe}_{2} \mathrm{O}_{3}\right)$ with some substitution of Si and $\mathrm{Al}$. The composition of calcium ferrite generated from magnetite depends on the amounts of $\mathrm{SiO}_{2}$ and $\mathrm{CaO}$ from silicate melt reacting with magnetite. The basicity (molc ratio of $\mathrm{CaO} / \mathrm{SiO}_{2}$ ) of silicate melt consumed in the reaction is around 2 .

\section{Acknowledgements}

The authors would like to express their appreciation to China Steel Corporation, Taiwan, and School of Materials, University of Sheffield, U.K., for supporting this work.

\section{REFERENCES}

1) F. Matsuno: Trans. Iron Steel Inst. Jpn., 19 (1979), 595

2) F. Matsuno and T. Harada: Trans. Iron Steel Inst.Jpn., 21 (1981), 318

3) M. Sasaki and Y. Hida: Tetsu-to-Hagané, 68 (1982), 563.

4) Y. Hida, K. Ito, J. Okazaki and M. Sasaki: Trans. Iron Steel Inst. Jpn., 24 (1984), B331.

5) L. H. Hsieh and J. A. Whiteman: ISIJ Int., 29 (1989), 24.

6) K. Inoue and T. Ikeda: Tetsu-to-Hagané, 68 (1982), 2190.

7) S. N. Ahsan, T. Mukherjee and J. A. Whiteman: Ironmaking Steelmaking, 10 (1983), 54.

8) P. Coheur: J. Iron Steel Inst., 207 (1969), 1291.

9) P. R. Dawson, J. Ostwald and K. M. Hayes: BHP Tech. Bull., 27 (1983), 47.

10) M. Sasaki and T. Nakazawa: Tetsu-to-Hagané, 54 (1968), 1217. 